\title{
Aquelarre en la Tierra del Sol Naciente: La importancia del Mefistófeles goetheano para el manga japonés
}

\section{Coven in the Land of the Rising Sun: the Importance of Goethe's Mephistopheles for Japanese Manga}

\section{Diego Hernán Rosain}

\author{
Facultad de Filosofía y Letras - RIIAM (UBA)
}

Diego Hernán Rosain (Argentina, 1991) es licenciado y profesor normal y superior en Letras por la Universidad de Buenos Aires (FFyL-UBA). Es adscripto a la cátedra de Teoría y Análisis Literario «C» a cargo de la Prof. Silvia Delfino con el proyecto titulado «Traicionar la tradición». Usos y funciones de las herencias y legados culturales en la producción crítica y literaria de Héctor Libertella» dirigido por la Prof. Guadalupe Maradei. Es miembro activo de la Red Latinoamericana de Investigadores y Organizaciones Sociales Latinoamericanos (RIOSAL) a cargo del Consejo Latinoamericano de Ciencias Sociales (CLACSO), de la Red Iberoamericana de Investigadores en Anime y Manga (RIIAM) y de la Asociación Latinoamericana de Estudios de Asia y África - Sección Argentina (ALADAA Argentina). Sus temas de investigación son la literatura argentina del siglo $\mathrm{xx}$, por un lado, y los cruces entre canon literario universal y manga y anime, por el otro. Ha publicado artículos en revistas como Puesta en Escena, Exlibris, BADEBEC, Orbis Tertius, Luthor, CuCo, Cuadernos de Cómic, Celehis, Trazos y Recial. Actualmente está preparando su proyecto de doctorado sobre Héctor Libertella y la tradición.

Fecha de recepción: 5 de enero de 2020

Fecha de aceptación definitiva: 21 de marzo de 2020 


\title{
Resumen
}

El manga es un soporte atractivo para narrar historias que son consideradas de un gran valor simbólico. La importancia de Goethe para la industria cultural japonesa se ve reflejada en tres tipos de producciones: aquellas que tratan el tópico del pacto con el diablo, aquellas que utilizan el nombre de sus personajes y aquellas que utilizan sus argumentos. En el siguiente trabajo analizaremos algunos de los mangas que hacen usos múltiples del pacto demoniaco para ver en qué medida el drama describe algunas condiciones de lo humano vigentes hasta nuestros días retomadas por la visión de los artistas nipones.

Palabras clave: Fausto, Goethe, manga, Mefistófeles, tópico

\begin{abstract}
The manga is an attractive support to tell stories that are considered of great symbolic value. The importance of Goethe for the Japanese cultural industry is reflected in three types of productions: those that deal with the topic of the pact with the devil, those that use the name of their characters and those that use their arguments. In the following work we will analyze some manga that make multiple uses of the deal with the Devil to see to what extent the drama describes some conditions of the human being valid until our days taken up by the vision of the Japanese artists.
\end{abstract}

Key words: Faust, Goethe, Mephistopheles, Manga, Topic

\section{Cita bibliográfica}

Hernán Rosain, D. «Aquelarre en la Tierra del Sol Naciente: La importancia del Mefistófeles goetheano para el manga japonés», en CuCo, Cuadernos de cómics n. ${ }^{\circ} 14$ (2020), pp. 41-61. 


\section{Introducción}

Como ya hemos analizado en trabajos anteriores,${ }^{1}$ hay mangas que hacen usos varios del canon literario universal. Esta afirmación, en apariencia inocente e irrelevante, abarca en realidad un enorme número de la producción nipona que no ha decaído conforme transcurrieron las décadas; por el contrario, como trataremos de demostrar, se ha visto acrecentada. Desde sus orígenes, tanto el manga como el anime emplearon fuentes literarias como inspiración para generar obras de lo más fidedignas a lo más originales posible. ${ }^{2}$ Hasta el momento, hemos reconocido al menos cuatro tipos de historietas japonesas que utilizan de un modo particular textos clásicos y que pueden ser abordados desde la perspectiva de la historia cultural o, en términos nipones, el bunkashi (文化史): ${ }^{3}$ las reformulaciones, que implementan de maneras múltiples y disímiles las tramas, temas y personajes universalmente conocidos y valorados en todo el globo ocultando a los héroes el hecho de que forman parte de un aparato intertextual (One Piece, Magi, Nanatsu no Taizai, Mahō Tsukai no Yome), y las adaptaciones, cuya función principal es la de traducir lo más fielmente posible dichas historias al lenguaje híbrido del manga o el anime para así divulgar y difundir las obras de autores de renombre y servir de incentivo y vía para la lectura de los clásicos literarios originales (el World Mas-

${ }^{1}$ Rosain, D. H. «Clásicos de ayer y de hoy: el manga como reescritura del canon literario universal desde las problemáticas niponas actuales», en Luthor. Entender, destruir y crear, n. ${ }^{\circ} 34$ (2017). Disponible en: http://www.revistaluthor.com.ar/spip.php?article175.

2 Hernández Pérez, M. Manga, anime y videojuegos. Narrativa cross-media japonesa. Zaragoza, Prensas de la Universidad de Zaragoza, 2017, pp. 48-50 y 194-195.

3 Seguimos en este concepto las definiciones de Peter Burke, para quien: «La historia cultural no es un nuevo descubrimiento ni una invención. Ya se cultivaba en Alemania con ese nombre (Kulturgeschichte) hace más de doscientos años. Antes de esa época, existían historias independientes de la filosofía, la pintura, la literatura, la química, el lenguaje, etc. De la década de 1780 en adelante, encontramos historias de la cultura humana o de la cultura de regiones o naciones particulares». Burke, P. ¿̨ué es la historia cultural? Barcelona, Espasa Libros, 2016, p. 19.

Tomamos cultura en su sentido etnográfico amplio, como una compleja totalidad que incluye los conocimientos, las creencias, el arte, la moral, el derecho, las costumbres y cualesquiera otras capacidades y hábitos adquiridos por el hombre como miembro de una sociedad: «Esta noción antropológica es la que han hecho suya los historiadores culturales (y otros miembros de su cultura) en la última generación, la época de la "antropología histórica" y de "la nueva historia cultural"». Ibid., p. 45.

Esto fue posible gracias a un giro antropológico que se produjo a nivel mundial en las décadas de los sesenta y los setenta y que posibilita que cualquier producto cultural se convierta en un objeto de estudio válido. La historia cultural sería aquella rama de la historia que analiza la cultura utilizando herramientas provenientes de otras ramas que no son oriundas ni privativas de la historia. Es un complejo entramado metodológico que exige una previa esquematización de procesos históricos, discursos sociales, sujetos humanos y herramientas interdisciplinarias. En nuestro caso, nos focalizamos en los cruces modernos que se producen entre el manga o historieta japonesa y canon literario universal desde un análisis socio-histórico. 
terpiece Theater, Seishun Anime Zenshū, Aoi Bungaku Series). ${ }^{4}$ Ambos subgéneros comparten el placer y el interés por recurrir a la literatura como motor para contar argumentos más o menos novedosos, pero que se revisten de cierto prestigio por el simple hecho de reutilizar textos de un potente e indiscutible valor simbólico para luego narrar problemáticas cercanas a los lectores nipones. ${ }^{5}$ Un tercer vértice está dominado por lo que dimos en llamar paralelismos, historias que cohabitan con sus intertextos reales dentro de la ficción que configuran y cuyos personajes pueden trazar un paralelismo más o menos consciente con ellas; los protagonistas conocen las obras cumbre sobre las cuales están influenciadas sus vidas, pero no tienen noción de su condición de criaturas ficticias, por lo cual es el lector antes que los personajes quienes pueden hallar semejanzas y diferencias entre el hipotexto y el hipertexto (Meitantei Conan, Tokyo Ghoul, Aku no Hana). Por último, encontramos las dicotomías, argumentos en los que los personajes encarnan a otro ser previo y por ende corren con la obligación de repetir su historia, o bien pueden optar por deshacerse de dicha envestidura a riesgo de perder su integridad (Saint Seiya, Neon Genesis Evangelion, Fate/Series). En cualquiera de los casos anteriormente mencionados, tanto el manga como el anime forman parte de un intrincado proceso de hibridación cultural, «una amalgama de rasgos culturales de Occidente y Oriente, que se puede apreciar tanto en historias de ambientación realista como de corte fantástico». ${ }^{6}$

Los motivos que llevan a los autores a apelar a la memoria cultural que se pretende global y regional a la vez no pueden catalogarse fácilmente ni mucho menos reducirse a unos cuantos objetivos; algunas de las razones por las cuales los autores nipones hacen uso del bagaje literario universal son descriptos por Kiyomitsu Yui, ${ }^{7}$ con los cuales concordamos. Es por ello que, en el siguiente trabajo, haremos un análisis entre distintos casos de mangas a los que catalogamos como reformulaciones y que emplean una obra en concreto para sus fines particulares, analizando los motivos que llevaron a esta elección y sus posteriores reinterpretaciones. El método de abordaje a aplicar será el ofrecido

\footnotetext{
${ }^{4}$ Un claro caso de adaptación de la historia clásica de Goethe es el Fausto codificado al lenguaje del manga por East Press y traducido al español por la editorial Herder. Un trabajo sobre los procesos de apropiación y traducción empleados para su confección bajo el título "Vade retro, akuma. Algunas aproximaciones al Fausto publicado por East Press” fue expuesto en el IX Simposio Internacional de Narratología: Irrupción de los nuevos modos de narrar organizado por la Universidad del Salvador en 2018. Las actas del mismo se encuentran actualmente en prensa.

5 «El proceso (de toda construcción cultural) está guiado en parte por la necesidad de adaptar viejas ideas a nuevas circunstancias, en parte por las tensiones entre formas tradicionales y nuevos mensajes, en parte por lo que se ha dado en llamar "el conflicto interno de la tradición”, el conflicto entre la tentativa de hallar soluciones universales para los problemas humanos y las necesidades o la lógica de la situación». Burke, P. Op. cit., p. 124.

${ }^{6}$ Hernández Pérez, M. Op. cit., p. 47.

7 Kiyomitsu, Y. «Japanese Animation and Glocalization of Sociology», en Sociologisk Forskning, vol. 47, n. 4 (2010), pp. 44-50.
} 
por las literaturas comparadas. ${ }^{8} \mathrm{El}$ autor en cuestión será Johann Wolfgang von Goethe (1749-1832) y el libro que escogeremos es Fausto (1773-1833). Creemos que tanto el autor como su producción son sumamente significativos ya que, dentro del imaginario nipón del manga y el anime, ambos representan la máxima expresión de la literatura alemana. ${ }^{9}$ Fausto es considerada una obra clave para lo que fue no solo el Sturm und Drang en Alemania, sino el movimiento que lo sucedió, el Romanticismo, en el resto del mundo. Este drama marcó un antes y un después en las corrientes de pensamiento estético y filosófico, pero también en un tópico narrativo tan importante y destacado como lo es el pacto con el diablo. Sin duda, la importancia que tiene el Fausto para la historia de la cultura está estrechamente ligada a las directrices que su autor implementó en una forma tan recurrente como lo fue y continúa siendo el trato entre los hombres y las fuerzas del mal para consumar metas que superan sus propias fuerzas. Sin embargo, no podemos someter la grandeza de esta tragedia únicamente a las innovaciones que Goethe ejecutó sobre el tópico. Más aún, tanto Fausto como Mefistófeles han cobrado materialidad real y ocupan hoy un lugar predominante en el inconsciente colectivo como también lo han hecho Don Quijote, Hamlet, Sherlock Holmes, la criatura de Frankenstein, entre tantos otros. ${ }^{10}$ Es decir, no podemos hablar ya del tópico en cuestión sin aludir a las contribuciones que Goethe y sus personajes han aportado a dicha tipología. Es por eso que es preciso realizar un estudio detallado y minucioso de aquellas reinterpretaciones niponas que se han llevado a cabo sobre la obra magna del escritor alemán y su pertinencia, haciendo particular hincapié en sus semejanzas y diferencias. Nos concentraremos, así, en los rasgos goetheanos y, puntualmente, en los aspectos mefistofélicos de algunos mangas.

\section{El diablo metió la mano: representaciones del demonio en la historieta japonesa}

Existen, ciertamente, estructuras fijas que funcionan sin importar las circunstancias ni los lectores. Es indudable que el hombre siente cierta atracción por la repetición ya

${ }^{8}$ Para ello, tomamos como aparato teórico los textos de Guillén, C. The challenge of comparative literature. Cambridge-London, Harvard University Press, 1993; Durisin, D. Theory of Literary Comparatistics. Bratislava, Slovak Academy of Sciences, 1984; y Franco Carvalhal, T. Literatura comparada. Sâo Paulo, Ática, 2007.

9 La historia de Fausto ingresó a Japón por primera vez en 1913 gracias a la traducción completa del literato, traductor y militar Mori «Rintarō» Ōgai (1862-1922), uno de los principales autores de la Restauración Meiji (1868-1912), y a una versión abreviada de la exégesis de la obra en cuatro volúmenes del filósofo e historiador alemán Kuno Fischer (1824-1907). En paralelo con estas publicaciones, Fausto fue también conocido en la Tierra del Sol Naciente bajo la forma de múltiples representaciones líricas. Es posible que Osamu Tezuka haya leído el drama y a la vez asistido a alguna de estas puestas en escenas operísticas del drama goetheano, hechos que conmovieron profundamente su conciencia y su pluma a tal punto de escribir tres versiones del mismo a lo largo de su vida. Para el mangaka, el empleo de la literatura en sus historietas permitía instaurar al noveno arte como un canal de gran importancia dentro de la cultura, legado que continúa vigente hasta nuestros días y que se ha catalogado bajo el nombre de gakushu o «manga educativo», historietas de gran valor simbólico y cuyo mensaje es preciso preservar y difundir.

10 Eco, U. Apocalípticos e integrados. Buenos Aires, Tusquets Editores, 2011 [1964], p. 191. 
que la constancia y la semejanza nos traen tranquilidad: la idea de un orden y un sistema de sentidos asegurados. ${ }^{11}$ Los tópicos literarios son eso: fórmulas más o menos fijas, difíciles de modificar, que varían mínimamente según el tiempo, el espacio y los autores, que utilizan temas, personajes y argumentos tan frecuentes que se vuelven parte indisociable de la historia cultural. Sin embargo, esto no significa pobreza de creatividad: un lugar común puede abrir camino a un producto novedoso y significativo para los lectores ya que cada armazón, cada elemento recurrente, crea nuevos significados; es decir, lo valioso no está en lo semejante, sino, más bien, en lo distinto, lo que se premedita. ${ }^{12}$

El pacto es un motor narrativo interesante por causas numerables: algunos suponen igualdad de condiciones, mientras que otros muestran una marcada asimetría entre las partes; un pacto puede cumplirse a rajatabla como puede modificarse, afianzarse, trastocarse, violarse o romperse; todo contrato implica una tensión entre la legalidad de la escritura y las acciones de los involucrados que brinda múltiples aristas de fuga. Todo pacto es, en fin, un fenómeno de negociación, vinculado a la comunicación, en una sociedad de respeto mutuo. ${ }^{13} \mathrm{Si}$ a esto le sumamos un hecho sobrenatural como la participación de un demonio, tenemos una fórmula más que atractiva para el lector: el diablo, encarnación del mal, alegoría del pecado e indicio de perdición, propone a un hombre cumplir cualquiera de sus fantasías a cambio del módico precio de su alma. Esos son los matices básicos de este tópico literario. La apariencia y actitud del diablo pueden variar, el pacto puede ser con sangre, tinta o palabras, el condenado puede salir invicto o sufrir ciertas consecuencias por culpa de su soberbia, pero eso dependerá de las intenciones de cada autor. Lo que queda claro es que lo que se obtiene es un relato altamente moralista que explora los límites y condiciones de lo humano.

Mefistófeles es un demonio propio del folclore alemán que nace en el siglo xvi. Su actitud es burlona, irrespetuosa y procaz, como la de muchos seres del inframundo; sin embargo, cuenta con un gran poder de convencimiento, un aparato retórico envidiable y un pensamiento crítico y lógico irrefutables. Simboliza, sobre todo, la pérdida de la fe, de la creencia en la hermenéutica cristiana y del amor a Dios. A su vez, también representa el modo de obrar según la moral que rige a las sociedades avanzadas en materia industrial y científica. Mefistófeles es un demonio de la modernidad porque representa al progreso, la potencia vital del Siglo de las Luces. Para una época en la que se gesta una fe ciega en la razón y la lógica, a la vez que los investigadores y letrados se alejan de la gracia divina, el método que desarrollan los hombres para avanzar en sus empresas epistemológicas debe suspender los juicios de valor éticos

${ }^{11}$ Hernández Pérez, M. Op. cit., p. 109.

12 Eco, U. Op. cit., pp. 213-214 y 217-218.

${ }^{13}$ Para más información sobre la semiótica del pacto ver Pérez Herranz, F. M. «Tópica de la negociación», en Cuadernos de Información y Comunicación, n. 8 (2003), pp. 17-38. Disponible en: https://revistas.ucm.es/index.php/CIYC/article/viewFile/CIYC0303110017A/7323. 
y morales para ser fructíferos. ${ }^{14}$ Esto se ve, sobre todo, en otro tópico literario como lo es el del científico loco, cuya variante en Goethe se halla en el aprendiz de brujo: ambos aspiran a ser grandes en su campo, desoyendo las críticas y observaciones de sus colegas. ${ }^{15}$ Esto desata el prodigio, a la vez que descarrila las riendas del proyecto personal. Para el siglo XIX, pleno auge del positivismo y la aceleración de la experiencia, la única posibilidad que pareciera tener el hombre de ocupar el rol de demiurgo es dejando atrás las valoraciones sobre su obra.

Ahora bien, no es casual que Japón haya tomado como arquetipo de figura demoniaca a este personaje legendario. Para empezar, no son insignificantes los vínculos históricos que unieron por décadas el archipiélago con la tierra de los godos. A partir de su apertura económica y mercantil durante la Restauración Meiji (1868-1912), la atención nipona recayó puntualmente en las grandes potencias de Occidente, siendo Alemania de las más atractivas. ${ }^{16}$ Desde la adopción de un modelo pedagógico prusiano para su implementación en las universidades estatales, ${ }^{17}$ hasta las relaciones político-militares emprendidas durante ambas Guerras Mundiales — primero como enemigos, luego como aliados-, Japón ha tenido un profundo y sincero respeto por la cultura germánica. Pero, sin duda alguna, la persona más influyente dentro de la industria cultural en lo que se refiere a la percepción nipona de Alemania fue Osamu Tezuka, el creador de Astroboy, quien desde una valoración positiva y fructífera sobre el rol que juega la literatura en la sociedad y desde sus múltiples producciones basadas en clásicos literarios (entre las cuales Fausto ha contado con un lugar privilegiado) ${ }^{18}$ contribuyó de manera efectiva a asentar en el imaginario colectivo de la Tierra del Sol Naciente a los protagonistas de la obra de Goethe. Sin embargo, el drama de Fausto, en general, y la figura de Mefistófeles, en particular, no suelen estar recubiertos por un halo benévolo y optimista. Por el contrario, el demonio occidental suele ser implementado, como veremos al final de este trabajo, como una materialización de determinados aspectos nocivos de Occidente importados y actualmente muy arraigados en la sociedad en detrimento de otras virtudes tradicionalistas japonesas y valoradas

14 «Uno de los personajes goetheanos en que mejor encarna la nueva era es el Mefistófeles de Fausto: en las palabras de este demonio se expresa el lenguaje del materialismo de los siglos XviI y xviII, como también la filosofía y la ética individualistas de la burguesía; no en vano es el encargado, en la segunda parte de la obra, de introducir el dinero, de promover en el pequeño Estado la expansión colonial y de contribuir a que Fausto se convierta en empresario capitalista». VEDd, M. Leer a Goethe. Buenos Aires, Quadrata, 2015, p. 33.

15 Gasparini, S. Espectros de la ciencia. Fantasías cientificas de la Argentina del siglo XIX. Buenos Aires, Santiago Arcos, 2012, pp. 121-122.

16 Hernández Pérez, M. Op. cit., p. 52.

17 Braslavsky, C. «La historia de la educación y el desafío contemporáneo de una educación de calidad para todos», en Ruiz Berrio, J. (ed.). Pedagogía y Educación Ante el Siglo XXI. Madrid, Departamento de Teoría e Historia de la Educación de la Universidad Complutense de Madrid, 2005, pp. 269-286.

${ }_{18}$ Rosain, D. H. (2020), Op. cit. 
positivamente por siglos. ${ }^{19}$ Será por esto pertinente definir en qué medida existen demonios mefistofélicos que encarnan esta invasión y ataque a los cimientos de la comunidad nipona y otros que sirven solo a fines estéticos y diegéticos sin implicar una crítica patente.

\section{Casi, pero no tanto: algunos casos relevantes de pactos con el diablo}

El pacto con el diablo es de los tópicos más utilizados en el manga y el anime de fantasía, aunque presenta matices particulares. Podemos citar las obras de Yana Toboso y Yūsei Matsui, autores de Kuroshitsuji (黒執事, «El Mayordomo Negro», 2006) y Majin Tantei Nögami Neuro (魔人探偵 脳噛ネウロ, «El Demonio Detective Devora-Memorias Neuro», 2005), respectivamente. El primero transcurre en Inglaterra, durante la época victoriana. Ciel Phantomhive, primogénito del conde Vincent Phantomhive, hereda a la temprana edad de doce años el título nobiliario y la empresa de juguetes de su familia tras la trágica y misteriosa muerte de sus padres. Como consecuencia de este desastre, un todavía inocente y desamparado Ciel invoca accidentalmente al demonio Sebastian - en medio de un rito satánico donde él era la víctima objeto de sacrificio- y decide realizar un pacto con él en donde cede su alma a cambio de cobrar venganza por el asesinato de sus progenitores. Sebastian acepta el contrato y desde entonces sirve como el leal mayordomo de Ciel, con el que resolverá una serie de crímenes para la reina Victoria hasta hallar a los culpables de su propia desgracia. Sebastian posee dos formas: una humana, la de un sirviente jovial, sensual, delicado, de tez blanca y ojos carmesíes, buenos modales, cordial, servicial, inteligente, misterioso y con facultades extraordinarias; y otra demoniaca que, si bien aún no se ha mostrado de forma completa, consta de unas botas de tacón alto, plumas negras, garras afiladas y colmillos pronunciados. A pesar de cumplir con su palabra, el único deseo que impulsa a Sebastian es obtener el alma de su amo y no toma recatos en decírselo.

En el segundo caso, la acción transcurre en el Japón moderno. Yako Katsuragi es una estudiante de Secundaria que ha perdido a su padre en un violento asesinato a puertas

${ }_{19}$ En este punto, Manuel Hernández Pérez analiza los rasgos híbridos entre Oriente y Occidente que adoptan el manga y el anime, entre ellos las tramas y temas, y cita a la autora Amy Shirong Lu (2008) para mostrar distintas posturas frente a lo foráneo. Desde su perspectiva, las ilustraciones de personajes occidentales tienden en muchos casos a una demonización del hemisferio ya que «la representación de caracteres extranjeros es resultado de respuestas a la hegemonía de potencias extranjeras, normalmente europeas o norteamericanas, en la más pura tradición de algunos estudios culturales». Hernández Pérez, M. Op. cit., pp. 50-51.

Por su parte, el autor desmiente a Lu y opina que «la mera presencia de elementos que podemos reconocer como occidentales [...] puede responder a diversos intereses comerciales, artísticos e incluso políticos, sin que ninguna de estas causas prevalezca sobre las demás». Ibid, p. 51.

Seremos criteriosos en cada caso sobre cuál es el acertado significado que los mangaka dan a sus demonios. 
cerradas, por lo cual la policía opta por cerrar el caso bajo la rótula de suicidio. En medio del luto aparece Neuro, un demonio que viene al mundo de los humanos para alimentarse de nuevos misterios ya que los del infierno no han conseguido saciar su voraz apetito. Neuro promete a Yako que, si se convierte en una detective juvenil para permitirle consumir enigmas policiales, él la ayudará a encontrar al verdadero asesino de su padre. Así, ambos sellan el pacto y comienzan una agencia de detectives en la cual la verdadera mente operante es el demonio bajo el disfraz de humilde asistente. Neuro viste un traje de color azul, sus dientes son particularmente puntiagudos, su cabello llamativamente colorido y sus ojos verdosos hipnotizantes; frente a los extraños, actúa como un adulto responsable, ingenuo y amable, pero, detrás de esa máscara, oculta una personalidad sádica, agresiva, posesiva y glotona. Para resolver casos cuenta con setecientas setenta y siete armas demoniacas que le sirven de herramientas e instrumentos forenses. En cambio, para devorar misterios, solo le basta convertir su cabeza en la de un pajarraco gigante y masticar a sus víctimas, sin asesinarlas, pero ocasionándoles serios trastornos a nivel físico y mental.
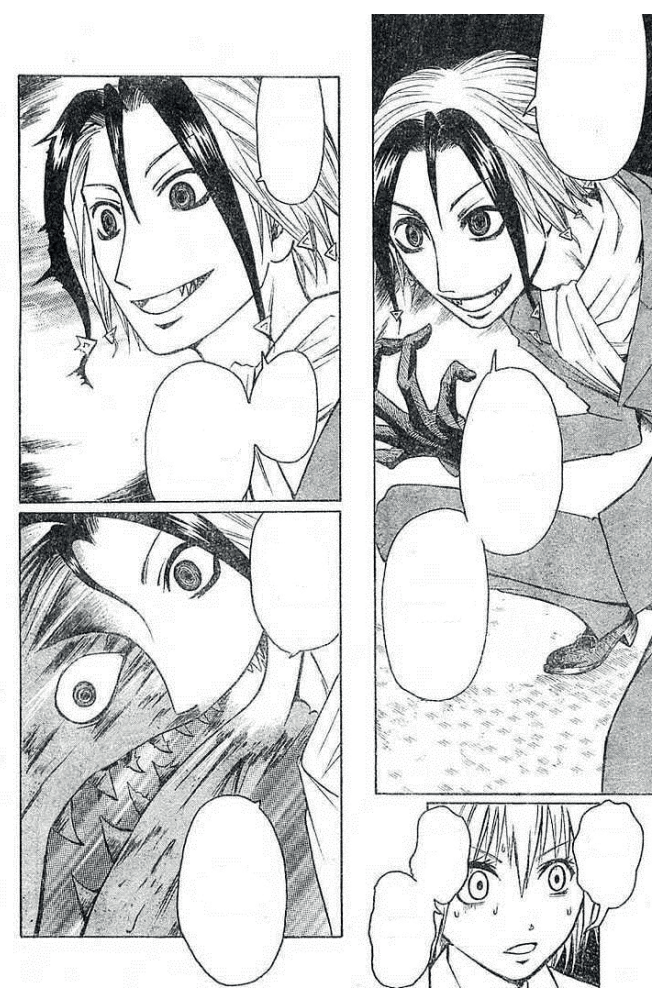

FIG. 1. Matsui, Y. Majin Tantei Nögami Neuro. Tokyo, Shūeisha, 2005, cap. 1, p. 12. (C) 2005 by Yusei Matsui All rights reserved. First published in Japan in 2005 by SHUEISHA Inc., Tokyo. Spanish translation rights in Spain arranged by SHUEISHA Inc. through VME PLB SAS, France. 
Hasta aquí el tópico del pacto con el diablo funciona en el manga como un dispositivo disponible para que los autores configuren sus historias. Sin embargo, no todo pacto con un demonio hace gala de ciertas características goetheanas ni todo diablo es, a su vez, una figura mefistofélica. ${ }^{20}$ Ambos tientan y acompañan incesantemente a sus presas - Sebastian, sobre todo, en tanto sirviente de Ciel como Mefistófeles es paje del Doctor-. Tanto Sebastian como Neuro son comparables a Mefistófeles; empero, no podemos reconocer rasgos suficientes como para asociarlos directamente con su predecesor. ${ }^{21}$ Más aún, Neuro está más cerca de ser un par de Fausto antes que de su contratante ya que, al igual que el científico y alquimista, aspira a conocer la verdad detrás de los misterios que rigen el universo. Incluso podemos encontrar repeticiones de la unidad argumental del tópico en otros mangas sin la necesidad de que haya un demonio en sentido estricto.

A modo de ejemplo, en Pandora Hearts (パンドラハーツ, «Corazones de Pandora», 2006) de Jun Mochizuki, Oz Bezarius, un adolescente que está a punto de cumplir la mayoría de edad y heredar un ducado, es secuestrado por una banda de encapuchados que lo destierran a una prisión en el Abismo, una dimensión oscura llena de criaturas horribles. Una vez allí, un enorme conejo negro llamado Alice, que había intentado rescatarlo y proclamarlo como suyo, le propone a $\mathrm{Oz}$ firmar un pacto en el que él será

${ }^{20}$ En este punto coincidimos con la distinción que realiza Eco sobre un personaje tipo en oposición a un símbolo o un lugar común: «El símbolo se diferencia también del tipo en que puede perfectamente preexistir a la obra como elemento de un repertorio mitológico, antropológico, heráldico, mágico. Puede preexistir como "lugar" originariamente literario y actualmente oculto en el convencionalismo, como situación cotidiana que la literatura ha hecho tópica y cargada de posibilidades alusivas [...], puede existir como "idea arquetípica", manifestación del inconsciente colectivo de que nos habla Jung [...]. En cambio, el tipo no preexiste jamás con respecto a la obra, sino que constituye su relación. Nada impide que el tipo como relación se haga popular y pase a formar parte de un "lugar" de repertorio». Eco, U. Op. cit., p. 208.

La potencialidad del tipo reside en su gran capacidad de asimilación y recuperación constante: «El tipo que se forma como resultado de la acción narrada o representada es, pues, el personaje o la situación lograda, individual, convincente, que queda en la memoria. Puede ser considerado como típico un personaje que, por el carácter orgánico de la narración que lo produce, adquiere una fisonomía completa, no solo exterior, sino también intelectual y moral. [...] se da en un personaje persuasivo, capaz de ser sentido por el lector como profundamente verídico, incluso allí donde dicho personaje no manifiesta su conexión con el mundo, su modo de actuar sobre las cosas y su personalidad, sino precisamente su impersonalidad, su ausencia de conceptos, su modo de sufrir las cosas sin rebelarse». Ibid., pp. 200-201.

${ }^{21}$ Encontramos muchas similitudes entre Sebastian y Neuro porque su construcción y su entorno son virtualmente similares. Por un lado, ambos demonios están configurados a partir de un pecado capital: el primero se identifica con la lujuria mientras que el segundo con la gula. Por otro lado, si bien los contextos varían en uno u otro, ambos forman parte de una trama que hace uso del género policial y de misterio. Es muy frecuente hallar cruces entre el relato detectivesco y otros géneros en el manga como lo son la ciencia ficción y la fantasía. Aun cuando parecieran ser incompatibles (un enigma es aquello que puede dilucidarse por medio de una investigación, mientras que el género fantástico busca desconcertar al lector por medio de los múltiples referentes e interpretaciones posibles) la unión de ambos crea un nuevo orden de verosimilitud fácilmente aceptable y asimilado por el lector de manga y el espectador de anime. 
su contratista a cambio de salir de allí. Por la selección en la nomenclatura percibimos que este manga exhibe mayores reminiscencias a Las aventuras de Alicia en el país de las maravillas (1865) de Lewis Carroll y a El maravilloso mago de Oz (1900) de Lyman Frank Baum antes que a Fausto. Lo mismo ocurre con Puella Magi Madoka Magica (魔法少女まどかえマギカ, «Madoka Magica, la chica mágica», 2011), anime dirigido por Akiyuki Shinbo y escrito por Gen Urobuchi, en el que Kyubey, un ser evolucionado perteneciente a una raza de extraterrestres ancestrales, convence a un grupo de niñas de hacer un contrato con él en donde se compromete a cumplir su sueño más anhelado a cambio de brindarles poderes mágicos que deberán utilizar para combatir a unos seres llamados Brujas, entre ellas la más poderosa, nombrada como La Noche de Walpurgis — un claro guiño a Fausto - , sin revelar sus verdaderas intenciones. En estos casos, el pacto perdura, pero no así la figura de Mefistófeles.

Una de las condiciones para que un pacto con el diablo pueda ser considerado mefistofélico pareciera ser, en el caso del manga, la implicancia de cierta hermenéutica religiosa y una aproximación a las prácticas y rituales cristianos, así como a sus representantes y actores más importantes. La presencia de ángeles en el caso de Kuroshitsuji, que además solo aconteció hasta el momento en el anime, no basta para generar esta lectura goetheana; ${ }^{22}$ pero, como veremos a continuación en los dos casos restantes, la presencia de instituciones religiosas y de un cuerpo de fervorosos creyentes que ponen en progresiva crisis y riesgo su propia fe en la divinidad y confianza en el progreso a partir de sucesivos encuentros con seres sobrenaturales genera los que consideramos los demonios más representativos del drama fáustico en el cómic japonés.

\section{Hablando del diablo: representaciones cabales de Mefistófeles en el manga}

Uno de los pocos casos en que podemos encontrar mayor afinidad con el Mefistófeles de Goethe es Ao no Exorcist (青のエクソシスト, «El exorcista azul», 2009) de Kazue Katō. En un mundo donde los demonios (provenientes de Gehenna) se han infiltrado en la Tierra (Assiah), los exorcistas son los únicos capaces de poner un tope al avance infernal. Jóvenes de todas partes son entrenados en academias especiales para tal misión. Una de ellas, la Escuela de la Verdadera Cruz ubicada en Japón, es dirigida por Mephisto Pheles, un exorcista de alto nivel condecorado con el título de Caballero Honorario. El verdadero nombre del director, con clara ascendencia demoniaca, es

22 A este respecto, Manuel Hernández Pérez opina que en el manga y el anime abundan «los elementos de religiones occidentales, que aparecen totalmente descontextualizados en lo que parece una burla o una crítica a sus principales ritos». Hernández Pérez, M. Op. cit., p. 195.

Esta excesiva referencialidad iconográfica desprovista completamente de sus significados originales es posible que exista en algunas cuantas historias con tramas humorísticas (en este caso con una función más paródica) o de poca rigurosidad bíblico-literaria. Sin embargo, en los dos casos que toma - el de Shin Seiki Evangelion y Ao no Exorcist- no solo se encuentra equivocado, sino que no logra ver la serie de sentidos que provoca la utilización de dicho imaginario cristiano en diálogo implícito o explícito con otros dogmas. 
Samael, ${ }^{23}$ aunque utiliza los alias de Mephisto y de Johann Fausto V en sociedad. Su apariencia es estrambótica: lleva un traje blanco con capa y sombrero de copa, una gola punteada en el cuello, unos pantalones bombachos, medias rayadas y botas terminadas en punta elevada. Sus colmillos pronunciados, su barbilla de chivo y sus orejas puntiagudas denuncian su condición demoniaca. Utiliza un paraguas maltrecho y remendado como bastón y a la vez como báculo para conjurar hechizos, aunque con pronunciar eins, zwei, drei y chasquear los dedos es suficiente para que realice magia. ${ }^{24}$ Entre sus trucos habituales está el de transformarse en cualquier animal, sobre todo en un perro pequeño similar a un fox terrier. ${ }^{25}$

Su personalidad es burlesca, por momentos aniñada e irresponsable, pero siempre está atento a los hechos, acechando, observando cada detalle e interviniendo solo cuando es necesario. Si bien es un demonio, manifiesta amar a los humanos. Aun así, no queda del todo claro de qué lado de la lucha se halla. Lo más probable es que ocupe una tercera posición, más bien con fines egoístas. Es un diablo apostador - rasgo típicamente mefistofélico, quien juega tanto con el Creador como con Fausto-, motivo por el que inventa excusas para no involucrarse en el devenir de la historia más de lo que debe. ${ }^{26}$ No se conoce a ciencia cierta cuándo emergió Samael, pero consta que ha vivido por

23 Samael, nombre con claras reminiscencias angélicas (la tradición hebrea lo identifica con el Ángel de la Fuerza bajo este nombre y el de Zeruel [Yalkut, I.110]) es, para la tradición gnóstica, uno de los nombres del Demiurgo. Así lo afirma Ireneo de Lyon en su Adversos Haerenses: «la serpiente despreciable tiene dos nombres, Miguel y Samael» (Adv. Haer. 1.30.9). Se lo caracteriza como «la serpiente despreciable» puesto que fue él quien cometió el pecado de equipararse con Dios, generando de este modo el origen del mundo visible. En palabras de García Bazán (parafraseando el segundo capítulo del gnóstico La hipóstasis de los Arcontes): «En el códice II [de los textos de Nag Hammadi] [...] Samael (el dios de los ciegos) dice la frase presuntuosa de Is. 46.9 aplicada a sí mismo y construye el orden inferior a imagen del superior, con lo que la potencia de Pistis-Sophía llegó hasta el abismo». En García Bazán, F. Gnosis: la esencia del dualismo gnóstico. Buenos Aires, Castañeda, 1978, p. 166. Sobre el nombre de Samael para el demiurgo, ver Scholem, G. Les origines de la Kabbale (cit. en Ibid., p. 85). En el manga, Samael es el segundo en la jerarquía de demonios en Gehenna, uno de los ochos reyes, el que controla el Tiempo y el Espacio (cap. 39, pp. 17-18). Allí mismo, Mephisto dice haber recibido otros nombres como Loki, Tramposo y Cuervo, insistiendo en su característica de mentiroso y creador de ardides.

${ }^{24}$ La preferencia de Mephisto por el idioma alemán en varias elecciones léxicas y nomenclaturas es significativa. A la vez, presenta una particular fascinación por la cultura otaku, la cual considera una desvergonzada conducta en pos del ocio y el entretenimiento. Allí, enuncia que el potencial humano radica en su imaginación y creatividad, competencias que los elevan al rango de ángeles o demonios. Katō, K. Ao no Exorcist. Tokyo, Shūeisha, 2009, cap. 39, p. 15.

${ }^{25}$ Recordemos que la primera aparición de Mefistófeles frente a Fausto es bajo la forma de un perro negro.

${ }^{26}$ En el capítulo 14 del manga, Mephisto, acusado de traicionar a la Orden de la Verdadera Cruz, en un juicio en el que se juzgan tanto sus actos como el hecho de haber ocultado la existencia e identidad del hijo de Satán, convence a los jueces de salvar su pellejo y asegurarse su propia posición a partir de una apuesta: Rin Okumura, protagonista de la historia, puede convertirse, en potencia, tanto en el legítimo heredero de Gehenna como en el más poderoso exorcista de la Orden y el arma más efectiva contra las huestes de Satán. Más adelante, uno de sus detractores destaca las habilidades influyentes y engañosas del demonio, resaltando su naturaleza táctica. 
siglos. En el capítulo 25 de la primera temporada del anime (2011), Samael cuenta que hizo un trato hace tiempo con un humano por medio del cual le concedía la juventud eterna para que experimentara todos los placeres y dolores conocidos por los hombres hasta que se sintiera satisfecho a cambio de su alma. Ese flashback remite indefectiblemente al argumento de Fausto, aunque, a diferencia de lo que ocurre en el drama, en el anime Mephisto le anuncia a su hermano que fue él quien ganó la apuesta.

En el capítulo 44 del manga, Mephisto, delante de una cortina negra, habla directamente con el lector y enuncia que, como demonio, considera que los humanos son fundamentalmente dirigidos por tres deseos: el material, el sexual y la sed de conocimiento. Para él, el patético impulso por conocer es más pertinaz y determinante que cualquier otro deseo: es lo que justifica el instinto de supervivencia. Él no es el enemigo, pero sin duda controla a todos los jugadores a su voluntad y antojo. Sus alumnos no son más que marionetas manipulables y él es el titiritero. ${ }^{27}$ Hay un tono desmesuradamente burlón en este discurso, ya que pone al mismo nivel el ansia por saber qué sucederá en el siguiente capítulo de una serie al anhelo por develar los misterios del universo. ${ }^{28}$ Aquí Mephisto actúa de la misma manera que su alter ego literario: su objetivo queda relegado a un segundo plano ya que encuentra placer en reordenar el tablero a su favor, de forma que hace del contrincante - sean los exorcistas u otros demonios- una pieza más del juego. Todo lo que sale de su boca pierde cierto carácter noble; ambos diablos corrompen las empresas elevadas y las rebajan a meras trivialidades egoístas y banales.

El otro caso que sigue la misma línea de Ao no Exorcist es, sin duda alguna, D. GrayMan (ディー・グレイマン, 2004) de Katsura Hoshino. E1 título no remite a Fausto, pero sí a otra obra con reminiscencias goetheanas que es El retrato de Dorian Gray (1891) del autor irlandés Oscar Wilde. La acción del manga transcurre en un mundo ficticio a fines del siglo xIx; la trama hace uso del género steampunk, por lo cual el lector puede toparse con máquinas e inventos anticuados pero, a su vez, demasiado modernos para el contexto en que se desarrolla la acción, en un cruce entre ciencia ficción y fantasía. La Congregación de la Sombra, una rama activista de la Iglesia especializada en exorcismos, magia, artefactos religiosos conocidos como «Inocencia» (イノセンス) y combates contra demonios, tiene como objetivo derrotar a Adam, mejor conocido como el Conde del Milenio, ${ }^{29}$ un ser de siete mil años de existencia,

27 Katō, K. Op. cit., pp. 20-21.

${ }^{28}$ Inmediatamente después de dicha explicación, se ve cómo el hermano del protagonista, Yukio Okumura, sella un pacto con sangre - el Contrato Morinas o el Contrato Vinculante del Demonio- a partir del que promete contribuir y dar información sobre una investigación, mas no puede hacer ninguna pregunta ni revelar nada de lo dicho durante la sesión ya que, de hacerlo, el demonio que creó el documento lo cazaría hasta cobrar venganza. Esta continuidad vincula a Mephisto con el pacto demoniaco sin necesidad de ser él quien lo inicie.

${ }^{29}$ El verdadero nombre del Conde es, al igual que el del primer hombre, Adam. Según Mizuno Suzume (2019), el personaje está inspirado en el Conde de Saint Germain (1703-1784), un enigmático 
virtualmente inmortal, cuyo objetivo es aprovecharse del sufrimiento de los hombres proveniente del dolor que ocasiona la pérdida de un ser querido para crear súbditos artificiales llamados akuma (悪魔, «demonio»).

El Conde posee dos apariencias: como demonio es un hombre grotesco y robusto, casi redondo y caricaturesco, de tez gris, rostro largo, delgado y triangular, dientes afilados, sonrisa exageradamente fija, orejas puntiagudas, pequeños cuernos en lugar de cabello y anteojos de quevedos que dejan ver por momentos unos pequeños ojos expresivos; su forma humana es, en cambio, más armónica: la de un joven hombre maduro y fuerte pero desaliñado, con barba y bigote ralos, cabellos desprolijos, tez morena y mentón fuerte. En ambos casos, viste un traje típico de la época victoriana: un esmoquin, camisa, corbata, sombrero de copa y un paraguas con una calabacita en la punta que le sirve para convocar demonios, el cual reemplaza por una gran espada negra de hoja ancha para luchar cuerpo a cuerpo. Se mueve en los círculos de la clase adinerada, quien lo reconoce y con la cual probablemente hace negocios, y lleva una vida digna de cualquier aristócrata. El Conde parece ser una persona muy alegre, amable, excéntrica y despreocupada, aunque en ningún momento oculta sus verdaderas intenciones. Es divertido y cómico, se comporta de manera caprichosa e infantil a pesar de ser la cabeza de la familia Noé, discípulos del profeta tras el acontecimiento del Diluvio Universal, por cuyos miembros se preocupa en los momentos de abatimiento. Sin embargo, en los últimos capítulos demostró ser temperamental, colérico, brutal y desquiciado cuando sus planes no marchan como él espera. También ha demostrado cierta compasión aparente, permitiendo que Allen Walker, protagonista y enemigo jurado, se convierta en miembro de los Noé al descubrir su naturaleza híbrida.

Como dijimos, el objetivo del Conde es arrasar con los humanos al igual que ocurrió durante el Diluvio para así hacer borrón y cuenta nueva en la Historia. Todos los hombres tienen genes de Noé en su sangre, por lo cual él debe buscar a los descendientes del profeta en cada generación. Sin embargo, su fuerza no es suficiente para alcanzar sus metas y es por eso que crea demonios artificiales con las almas de los difuntos. El modus operandi es siempre el mismo: un hombre llora la pérdida de un ser amado; de repente, aparece el Conde con una propuesta irrechazable: devolver al ser querido sin daños ni secuelas en un recipiente nuevo. El artífice necesita de la voz de los penitentes ya que ellos pueden invocar el espíritu de aquellos con los cuales mantuvieron un lazo afectivo en vida. Al calor de los acontecimientos, todas las personas aceptan gustosas sin medir las consecuencias de sus deseos egoístas y antinaturales. Acto seguido de la confirmación del pactante, el Conde incrusta el alma del difunto - la cual ya no tiene voluntad propia - en el esqueleto metálico del demonio

personaje del siglo Xviı cuya imagen está asociada a múltiples empresas de temática ocultista. De esta manera, nos damos cuenta de que, tanto en el Conde del Milenio como en Mephisto Pheles subyace un sustrato histórico-legendario vinculado con la magia y la alquimia. 


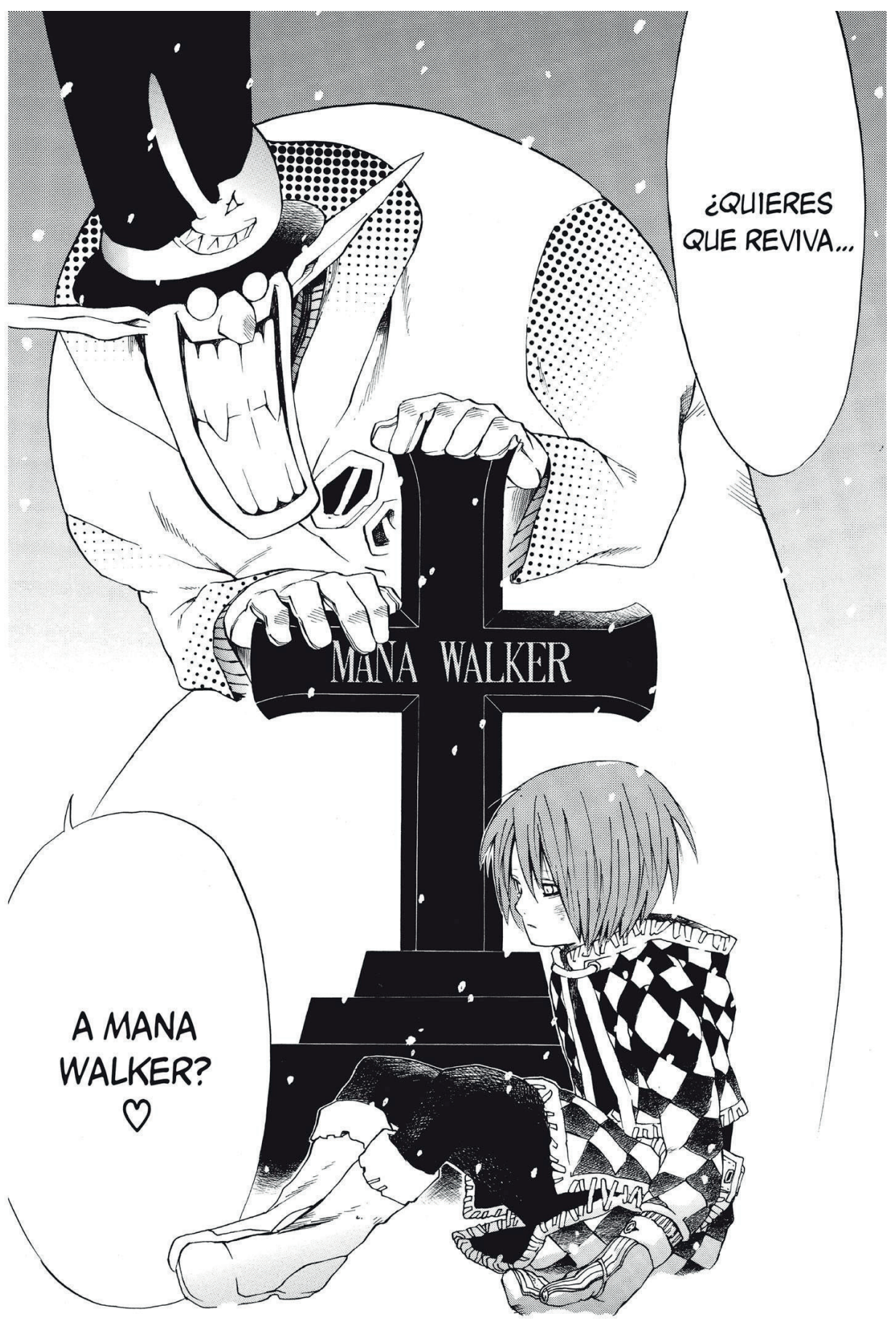

FIG. 2. Hoshino, K. D.Gray-Man. Tokyo, Shūeisha, 2004, cap. 3, p. 14. D. GRAY-MAN (C) 2004 by Katsura Hoshino/SHUEISHA Inc. edición española (C) Editorial Ivrea S.L. 
hecho de materia oscura y ordena a su creación atacar a aquel que hizo el petitorio para poseer su cuerpo. Así, los demonios del Conde constan de tres partes: el alma de un muerto, una estructura artificial y un cuerpo de carne y hueso que funciona como contenedor para la posesión. El demonio irá evolucionando a medida que vaya cometiendo atrocidades, desarrollando habilidades particulares, mutando de forma y corrompiendo el alma humana que en él habita para servir mejor al propósito de su amo mientras el espíritu es consumido por el odio hacia el mundo de los vivos. Las almas condenadas solo pueden ser liberadas de su tortura por medio de la Inocencia, ya que cualquier otro método provoca no su purificación, sino su destrucción total. La única persona que logró escapar al pacto hecho por el Conde es el joven Allen Walker, cuyo destino está estrechamente ligado a los Noé y cuyas acciones escapan casi por completo al entendimiento de su némesis.

En D. Gray-Man es determinante la relación que entablan el Conde y Allen, ya que la historia puede ser resumida a través de su lucha encarnizada, en la cual cada oponente representa las fuerzas del bien y el mal, aunque no queda del todo claro cuál es cuál. Allen, reencarnación del decimocuarto Noé, fue quien en otra vida traicionó al Conde para ocupar su lugar como cabeza de la familia. Desde entonces, ambos interpretan una tragicomedia, en el sentido dramático del término: el Conde es el payaso Augusto, impertinente y travieso que desbarata cualquier iniciativa, mientras que Allen es el payaso Blanco, serio y autoritario que arregla los desmadres y coloca en su lugar al Augusto. ${ }^{30} \mathrm{La}$ idea de escenario y de farsa rondan constantemente la trama, ya que se da a entender que hay mucho más en juego de lo que los actores creen saber. El exhibicionismo, la mostración, la parafernalia y el show son características tanto del Conde como de Mephisto Pheles, rasgos dramáticos y teatrales que quizás hayan sido adoptados del género al que pertenece Fausto. Más aun, la concepción de la Historia como farsa, retomada de El Dieciocho Brumario de Luis Bonaparte (1852) de Karl Marx, puede hallarse ya en la segunda parte del Fausto escrita durante la última etapa de la vida de Goethe, quien ya veía resquebrajarse los firmes cimientos de su época. ${ }^{31}$

Entonces es lícito preguntarse: si la Historia se repite desde hace milenios como una farsa cuya tragedia es ya irrecuperable y conocida tan solo por unos pocos actores inmortales y privilegiados, ¿quién de los involucrados ostenta la correcta interpretación de la Historia? ¿Es acaso mejor elaborada o más creíble la farsa de una época que otra? En el caso de los mangas, ¿por qué la Iglesia no hace caso a los designios de los Noé, que son los discípulos directos del profeta, y sí hace caso a Mephisto, que es un demonio con todas las letras? ¿La Modernidad no será, acaso, un nombre refinado para la farsa que los hombres continúan interpretando o, peor aún, improvisando?32

${ }^{30}$ Hoshino, K. Op. cit., cap. 89, p. 4. Para más información sobre los tipos de payasos ver JARA, J. El clown, un navegante de las emociones. Barcelona, Octaedro, 2014.

31 VedDa, M. Op. cit., pp. 27 y 31.

32 Ibid., p. 32. 
D. Gray-Man y Ao no Exorcist muestran las fallas de un sistema eclesiástico que convive con un discurso industrial y científico a la vez que va perdiendo lentamente poder y jurisdicción en ámbitos y esferas donde otrora gobernaba. Desde una interpretación metafórica, también muestran las incongruencias que existen entre los cruces y la pervivencia de los discursos hegemónicos que se repelen y contradicen entre sí: las comunidades humanas siempre crean aberraciones de la naturaleza que acaban por volverse en su contra. ${ }^{33}$

El Conde y Mephisto forman parte de un mismo entramado demoniaco cuyo cauce nace en el personaje cristalizado por Goethe. Ambas invenciones exhiben un trasfondo que los vincula no solo a las artes escénicas, sino que permiten percibir un devenir histórico - el de la Modernidad, con la fe y la confianza puestas en la ciencia, la industria y el progreso y distanciadas de la comunión con Dios, así como también de cualquier valoración ética y moral- bajo la tipología de la farsa. ${ }^{34} \mathrm{~A}$ su vez, el demonio marca los límites de las fuerzas humanas y de las posibilidades del hombre para ocupar el rol de demiurgo en los tiempos que corren. Mefistófeles, en estos mangas analizados, encarna dos males igualmente dañinos para la comunidad a la cual pertenece el lector japonés: por un lado, la tentación de caer en un falso aunque atractivo modelo capitalista de producción que organice y estructure la sociedad nipona, más acostumbrada y acomodada imaginariamente a una forma de vida vinculada a la armonía con la naturaleza y la simpleza de las pequeñas agrupaciones, en lugar de la burocratización y el desenfreno industrial de las ciudades modernas; por el otro, un reconocimiento de las limitaciones y la imposibilidad de autosuperación de los seres humanos como seres imperfectos e incapaces de lograr absolutamente todo lo que se proponen. Estas lecturas no solo atacan dos de los pilares sobre los cuales se ha fundado y sostiene la cultura del archipiélago - la defensa y el fomento de las costumbres y la capacidad de crecimiento personal y grupal—, sino que también parecieran perforar directamente los preceptos sobre los que se organiza el género shōnen, en el que se inscriben ambos mangas. ${ }^{35}$

33 «La actitud de Goethe frente a su época oscila, pues, entre una reconciliación con la frágil provisoriedad de la vida moderna y un distanciamiento crítico asociado a la búsqueda de principios inalterables, cimentados en la naturaleza [...]. La obra goetheana está íntegramente atravesada por el horror a la catástrofe: por el horror, en el plano material, de que el capitalismo en plena expansión tenga un efecto aniquilador sobre el mundo natural y el social; en el plano ideológico, de que el desamparo trascendental al que el proceso de secularización habría expuesto al hombre moderno deje a este sin parámetros éticos claros y lo sumerja en el relativismo. La justificación del orden natural es la respuesta de Goethe ante una era en la que los seres humanos han sido abandonados por la mano de Dios, y deben escoger por sí mismos, como adultos, las propias metas y caminos». VedDA, M. Op. cit., pp. 25-26; las cursivas son suyas.

34 «[En Fausto] las categorías morales convencionales, incluyendo la culpa, poseen una validez muy limitada y pertenecen al orden de lo superficial y aparente. A contrapelo del moralismo pequeñoburgués, la visión del mundo que [la obra proporciona] atribuye una validez decisiva a fuerzas naturales que, como veremos, anteceden y exceden las coyunturas sociohistóricas particulares». Ibid., p. 17.

35 Hernández Pérez, M. Op. cit., pp. 166-169, 189 y 194. 
De esta manera, entendemos que, aunque el origen del que derivan las lecturas sobre Mefistófeles es alemán, las interpretaciones que se prestan al diablo exceden esta nacionalidad para definir características perniciosas de Occidente desde un punto de vista local, ortodoxo y conservador. Aunque el capitalismo, la industrialización, la tecnocratización y la fe ciega en cualquier dogma o creencia han mostrado con creces sus falencias y los perjuicios que provocan, el hecho de of recer una mirada tan negativa al punto de alzarlos como máximos exponentes del mal y encerrarlos en una figura que ocupa el rol de némesis de los protagonistas solo puede entenderse desde la adopción de una postura que protege y enarbola las propias tradiciones como las benévolas y verdaderas, lo que dificulta producir una crítica bilateral y equivalente acerca de las decisiones e iniciativas impulsadas por Japón frente al devenir histórico de los acontecimientos sobre los que, además, ha tenido incidencia y en los que se ha visto involucrado. Estas historias parecieran mostrar cierta nostalgia por épocas más simples de antaño, sin proponer una respuesta que solucione las problemáticas dentro de las que Japón, así como el mundo entero, se halla actualmente imbuido.

\section{Conclusión}

Como hemos visto, la verdadera naturaleza de Mefistófeles es elucubradora, previsora, lúdica, perseverante y reticente. En este sentido, Sebastian y Neuro son personajes en los que el lector puede hallar ciertas reminiscencias del diablo alemán, pero cuyas características y aspiraciones no alcanzan para considerarlos figuras mefistofélicas. Mucho menos otros personajes como Alice, una Cadena o habitante del Abismo, o Kyubey, un extraterrestre colonizador con forma similar a la de un gato. La lista podría continuar con historias como Chrono Crusade (クロノクルセイド, 1998), High School DxD (ハイスクールD×D, 2008), Beelzebub (べるぜバブ, 2009) o Maoyū Mā̄ Yüsha (まおゆう魔王勇者, «El Rey Demonio y el Héroe», 2010) pero, como en los casos anteriores, solo encontraríamos leves estilemas de la obra magna de Goethe. ${ }^{36}$ Samael y Adam, en cambio, son los demonios más próximos a Mefistófeles que hemos podido hallar, no solo por los claros guiños intertextuales a Fausto, sino también por la impronta y los modos de obrar que guían a los archidemonios. Samael no es el mal encarnado, sino la burla a los logros y potencialidades de los seres humanos que confían plenamente en su condición. El Conde, a su vez, muestra las tensiones entre las lecturas bíblicas, las prácticas cristianas y la modernidad tecnificada en el marco de un mundo capitalizado. Como Mefistófeles, son más espectadores de la farsa que lleva a cabo una época antes que instigadores a la malicia. Ambos han demostrado que el tópico está lejos de agotarse y que puede ser revestido con envestiduras nuevas.

36 «En resumen, si por un lado los cómics ponen en circulación formas estilísticas originales, y bajo este punto se estudia no solo como hecho estético sino también como modificador de la costumbre, por otro cumplen una acción de homologación y difusión de estilemas, ya sea a título de mera depauperación ya a título de recuperación. No es posible un enjuiciamiento general de este proceso; es precisa una valoración histórico-crítico-pedagógica caso por caso». Eco, U. Op. cit., p. 163. 
Los ejemplos no dejan de resurgir para aquellos que deseen continuar explorando el alcance de la obra de Goethe en las producciones encasilladas dentro de la cultura de masas. Algunas con menor profundidad, otras de un gran alcance y valoración estética. Si el diablo Mefistófeles se mantiene en vigencia, se debe a la dificultad que tienen los sujetos en superar una crisis existencial y discursiva que ya mostraba sus primeros resquebrajamientos durante el caldo de ebullición que abrió paso al Romanticismo. De esta manera cerramos esta aproximación del manga en torno a Mefistófeles para darnos cuenta de que, así como una golondrina no hace al verano, un demonio no hace a la trama goetheana. 


\section{BibLIOGRAFÍA}

Braslavsky, C. «La historia de la educación y el desafío contemporáneo de una educación de calidad para todos», en Ruiz Berrio, J. (ed.). Pedagogía y Educación Ante el Siglo XXI. Madrid, Departamento de Teoría e Historia de la Educación de la Universidad Complutense de Madrid, 2005, pp. 269-286.

Burke, P. ¿Qué es la historia cultural? Barcelona, Espasa Libros, 2016.

Durisin, D. Theory of Literary Comparatistics. Bratislava, Slovak Academy of Sciences, 1984.

Eco, U. Apocalípticos e integrados. Buenos Aires, Tusquets Editores, 2011 [1964].

Franco Carvalhal, T. Literatura comparada. Sâo Paulo, Ática, 2007.

García BazÁn, F. Gnosis: la esencia del dualismo gnóstico. Buenos Aires, Castañeda, 1971.

Gasparini, S. Espectros de la ciencia. Fantasías cientificas de la Argentina del siglo XIX. Buenos Aires, Santiago Arcos, 2012.

Gerz, D. (ed.). Los evangelios gnósticos. Barcelona, Sirio, 2006.

Guillén, C. The challenge of comparative literature. Cambridge-London, Harvard University Press, 1993.

Harvey, W. W. (ed.). Sancti Irenaei episcopi Lugdunensis libri quinque adversus baerenses. Cambridge, Cambridge University Press, 1857.

Heredia Pitarch, D. Anime! Anime! 100 años de animación japonesa. Madrid, Diábolo Ediciones, 2016.

Hernández Pérez, M. Manga, anime y videojuegos. Narrativa cross-media japonesa. Zaragoza, Prensas de la Universidad de Zaragoza, 2017.

Horno López, A. El lenguaje del anime. Del papel a la pantalla. Madrid, Diábolo Ediciones, 2018.

Hoshino, K. D.Gray-Man. Tokyo, Shūeisha, 2004.

Jackson, R. «Lo “oculto" de la cultura», en RoAs, D. (ed.). Teorías de lo fantástico. Madrid, Arco/Libros, 2001, pp. 141-152. 
JARA, J. El clown, un navegante de las emociones. Barcelona, Octaedro, 2014.

Katō, K. Ao no Exorcist. Tokyo, Shūeisha, 2009.

Kiyomitsu, Y. «Japanese Animation and Glocalization of Sociology», en Sociologisk Forskning, vol. 47, n. 4 (2010), pp. 44-50.

Lu, A. S. «The many faces of internationalization in Japanese anime», en Animation: An Interdisciplinary Journal, vol. 2, n. ${ }^{\circ} 3$ (2008), pp. 169-187.

Matsui, Y. Majin Tantei Nōgami Neuro. Tokyo, Shūeisha, 2005.

Mizuno, S. «Analizando D.Gray-man. Noches 2 y 3: Una noche de luna llena y E1 Pentáculo», en Mistral Chronicles, 14 de mayo de 2019. Disponible en: http:// www.mistralchronicles.com/2019/05/14/analizando-d-gray-man-2-3-noche-luna-llena-pentaculo/

Palmer, P. M. y More, R. P. The Sources of the Faust Tradition. From Simon Magus to Lessing. New York, Oxford University Press, 1936. Disponible en: https://babel. hathitrust.org/cgi/pt?id=mdp.39015001147944;view=1up;seq=11

Pérez Herranz, F. M. «Tópica de la negociación», en Cuadernos de Información y Comunicación, n.o 8 (2003), pp. 17-38. Disponible en: https://revistas.ucm.es/ index.php/CIYC/article/viewFile/CIYC0303110017A/7323

Rosain, D. H. «Clásicos de ayer y de hoy: el manga como reescritura del canon literario universal desde las problemáticas niponas actuales», en Luthor. Entender, destruir y crear, n.o 34 (2017). Disponible en: http://www.revistaluthor.com.ar/ spip.php?article175

— «Vade retro, akuma: algunas aproximaciones al Fausto publicado por East Press», en Actas del Noveno Simposio Internacional de Narratologia: La Irrupción de los Nuevos Modos de Narrar. Buenos Aires, Universidad del Salvador, 2020 [En prensa].

Товоsо, Y. Kuroshitsuji. Tokyo, Square Enix, 2006.

VEdDA, M. Leer a Goethe. Buenos Aires, Quadrata, 2015.

Von Goethe, J. W. Fausto. Caseros, Gradifco, 2007. 